\title{
Forensic Engineering: Diagnosing Failures and Solving Problems
}

\author{
S. Neale Brian
}

Taylor \& Francis/Balkema, Leiden, The Netherlands; 2005: ISBN 978-0415-395236;

340pp; f109.50; hardback

Journal of Building Appraisal (2008) 4, 47-48. doi:10.1057/jba.2008.12

This is a compilation of papers presented at the Third International Conference of Forensic Engineering organised by the Institution of Civil Engineers. Forensic Engineering, to the average British engineer, would mean the activity of the Expert Witness who investigates engineering matters involved in legal proceedings. The papers presented at this Conference enlarge the meaning to encompass the investigation of all engineering failures; not just restricted to those ending up in Court.

Since time immemorial edifices created by man have fallen and systems evolved to deal with the results of the failures. The fact that buildings collapse is implicit in the earliest recorded Building Code attributed to the Babylonian King Hammurabi that states, among other things, that 'If a builder has built a house for a man, and has not made his work sound, and the house he built has fallen, and caused the death of its owner, that builder shall be put to death'.

Those of us involved in the Construction Industry may take comfort in the fact that the Code of Hammurabi has not yet been incorporated into the Construction Design and Management Regulations. This is not to suggest that the results of a serious engineering failure do not have dire consequences for the designers involved and it is in the interests of society as a whole, and engineers in particular, to ensure that the causes of failures are investigated and lessons learned.

Advances in structural design and building techniques in the distant past were the result of failures as design based on calculation and the theory of structures was unknown. The construction of numerous cathedrals throughout mediaeval Europe, which were successively higher and with greater clear spans, was a completely empirical process. The collapse of Beauvais Cathedral in France in 1284 resulted in the increasing use of flying buttresses to withstand the great horizontal forces transferred from the roof structure to the external walls. As recently as 1786 the West Front and Tower of Hereford Cathedral collapsed on Easter Monday, although some maintained this was result of Divine intervention.

Society no longer accepts that engineering advances should only be the result of lessons learnt from failures. Indeed, society no longer accepts that there should be any failures! Having practised as an Expert Engineer in the English courts for over 25 years I have formed the opinion that, regrettably, failures, like the poor, will always be with us. This is not to say that the position is acceptable and I believe that all practising engineers would greatly benefit from carefully considering a number of the papers published in this volume.

The two Keynote papers: 'Forensic investigation: the true calibrator for design limit states' and 'Quality and safety: The ultimate legacy of forensic engineering' should be compulsory reading for all engineering students. I will go further and state that they should be carefully studied by all practising engineers. The latter paper makes a valid 
point that young engineers should be exposed to the potential for failure and should be aware of why failures occur.

The catalogue of catastrophic structural failures in the 1970s and 1980s in the United States makes extremely sobering reading.

The papers presented in this volume are grouped under the following sections: Durability and assessment, Ground and marine, Failures of building envelopes, Incident/collapse investigation, Performance risk management, Legal and care considerations, and Educating for the future.

Many of the papers are of a somewhat esoteric nature and will only be of interest to engineers specialising in certain areas of civil and structural engineering. Engineers in general will, however, benefit from reading the papers that have a greater relevance to the design and construction process. One such paper, taken from 'Ground and marine', is: 'Forensic ground engineering assessment and timely disclosure of documents', by R.P. Thompson. This paper traces the history of the legal outcome of the failure of house foundations: the result of which was financial ruin for the firms involved. Much time and expense could be saved by engineers following the advice provided by Mr Thompson.

The papers published in the section of the volume titled: 'Failures of building envelopes' will be of more than passing interest to all Consulting Civil and Structural Engineers. I would hazard a guess that many who read the papers will breathe a sigh of relief and say 'There but for the grace of God go I!'

The paper by Keith Roberts, with whom I have been involved in a number of court cases, points out the potential hazards of specifying lightweight roofing systems, without having sufficient technical knowledge of possible causes of failure.

The average engineer may feel disinclined to study the papers in the sections: 'Incident/collapse investigation' and 'Performance risk management'. Among these papers, however, are nuggets of gold in the form of information that, once learned, could be of great assistance when considering the design process.

We cannot all have expertise in every branch of engineering and a consideration of the information provided may be of vital importance in educating an engineer to the need to seek specialist advice when his own knowledge is insufficient for the task in hand.

The penultimate section of the book: 'Legal and care consideration', contains papers dealing with matters that have been of concern to me for over a quarter of a century. The practising engineer might consider it unnecessary to know the implications of involvement in a failure, or alleged failure, that results in litigation. A knowledge of such a situation is, however, of great value and I consider that all will benefit from reading the words of wisdom contained within these papers.

'Educating for the future' is the title of the final section of the book, where advice is offered as to how the engineering professions should promulgate the knowledge gained from the investigation of structural failures. The suggestions made in the paper: 'A failures knowledge database for designers and constructors' would be of immense benefit to the engineering profession.

In conclusion I would advise all engineers, whether young or old, experienced or just commencing on their careers, to beg, borrow or steal a copy of this book: to become aware of its contents, to study those papers of particular interest and, above all, to gain an understanding of why failures occur and how they can be prevented. 